E3S Web of Conferences 1, 23002 (2013)

DOI: $10.1051 / \mathrm{e} 3$ sconf $/ 20130123002$

(C) Owned by the authors, published by EDP Sciences, 2013

\title{
Aerosol Trace Metal Concentrations over the Mediterranean Basin: observations through six cruise campaigns on board the CNR Research Vessel URANIA
}

\author{
$\underline{\text { M. Bencardino }}^{1}$, N.Pirrone ${ }^{1}$ and F. Sprovieri ${ }^{1}$ \\ ${ }^{1}$ CNR-Institute of Atmospheric Pollution Research, c/o: UNICAL-Polifunzionale, 87036 Rende Italy, \\ bencardino@iia.cnr.it
}

\begin{abstract}
The Mediterranean basin, due to its semi-enclosed configuration, is one of the areas heavily affected by aerosols. Despite implications on both human health and radiative budget involve an increasing interest, aerosol data are yet relatively scarce. In this work we show a dataset resulting from five ship-borne measurements performed, from 2003 to 2007, across the Mediterranean basin. Results involve daily fine $\left(\mathrm{PM}_{2.5}\right)$ and coarse $\left(\mathrm{PM}_{2.5-10}\right)$ particle size fraction concentrations as well as trace metal chemical analysis. According to aerosol optical properties and to chemical composition, continental aerosols, Saharan dust and maritime aerosols have been identified during the cruise campaigns. Shipping emissions, representing both local harbours and maritime traffic across the basin, were also tested using the marker ratio of $\mathrm{V}$ and $\mathrm{Ni}$, showing a quite large contribution to the total aerosol load. Spatial variability of the aerosol concentrations resulted in a larger fine concentration over the eastern Mediterranean sector compared with that resulted in the western one mainly due to the background contribution of anthropogenic compounds.
\end{abstract}

Keywords: trace metals, particle size fraction, Mediterranean basin, Saharan dust, shipping emissions

\section{Introduction}

From recent reviews it is apparent that the atmosphere is not only a significant, but in some cases, the dominant pathway by which metals and nutrients reach the ocean (Jickells, 1995). Atmospheric processes appear to play a primary role in supplying trace metals (Guerzoni et al., 1999), as well as nitrogen and phosphorus (Herut et al., 1999) to the Mediterranean Sea. The Mediterranean atmosphere appears to be one of the most polluted in the world (Kouvarakis et al., 2000) with a significant contribution of dense ship traffic and highly industrialized population centres surrounding the basin itself (Marmer and Lanmann, 2005). A large influence is also due to natural sources like Saharan dust and biomass burning (Pace et al., 2005). The transport of mineral dust and anthropogenic aerosols from land into the marine environment is of considerable interest, not least for its potential impact on ocean ecosystems, world climate and air quality. However, whereas there is already a large monitoring database measuring air pollution at surface land-based sites and in ports, there is a relatively little information on atmospheric aerosol directly measured at sea. In an attempt to fill in the gap of observations in the Mediterranean basin and to gain more insight into the atmospheric dynamical and chemical mechanisms leading to high surface aerosols levels, the Institute of Atmospheric Pollution of the National Research Council (CNR-IIA) has started regular ship borne measurements over the Mediterranean Sea since 2000. In the present paper we will focus on the aerosols observations in both the Western and Eastern Mediterranean Basin where a set a of measurement data were recorded during five cruise campaigns. Atmospheric aerosols concentrations and chemistry during a total of 83 days at sea travelling across the Mediterranean Basin were here reported. The analysis, contributes to understanding the causes of aerosol pollution in this area.

\section{Materials and Methods}

Aerosol measurements were performed during five cruise campaigns onboard the Research Vessel (R.V.) Urania of the CNR from $6^{\text {th }}$ to $27^{\text {th }}$ August 2003 , from $27^{\text {th }}$ October to $12^{\text {th }}$ November 2004 , from $17^{\text {th }}$ June to $1^{\text {st }}$ July 2005 , from $5^{\text {th }}$ to 20 July 2006 and from $13^{\text {th }}$ September to $2^{\text {nd }}$ October 2007. Specific tracks are reported in Fig.1. Measurement equipment were fixed on front of the ship to avoid contamination from the ship exhaust itself. Daily 24- 
$\mathrm{h}$ ambient $\mathrm{PM}_{2.5-10}$ and $\mathrm{PM}_{2.5}$ samples were otherwise collected using a Manual Andersen Dichotomous Sampler (Model 241) on 37ømm Teflon filters, over a 24-hour sampling period at a flow rate of $1.67 \mathrm{~L} \mathrm{~min}^{-1}$ and about $15 \mathrm{~L} \min ^{-1}$ respectively, for a total operational flow rate of $16.7 \mathrm{~L} \mathrm{~min}^{-1}$. Filters were conditioned and pre-weighed using a $1 \mu \mathrm{g}$ sensitivity microbalance (Gibertini Microcristal Model) in the laboratories of the CNR Institute of Atmospheric Pollution Research before and after the sampling period to assess $\mathrm{PM}_{2.5-10}$ and $\mathrm{PM}_{2.5}$ concentrations by standard gravimetric procedures. A total of 80 fine and coarse particulate samples were then collected along the performed tracks across the whole Mediterranean region (see Fig.6). Once the gravimetric determination was completed the filters were digested with $5 \mathrm{~mL}$ of a $10 \% \mathrm{HNO}_{3}$ solution and subsequently analysed for their elemental composition using an Inductively Coupled Plasma Mass Spectrometer (ICP-MS, Agilent Technologies, model $7500 \mathrm{CE}$ ). Concentrations of As, $\mathrm{Cd}, \mathrm{Cr}, \mathrm{Cu}, \mathrm{Mn}, \mathrm{Ni}, \mathrm{Pb}, \mathrm{Sb}$ and $\mathrm{V}$ were determined in all samples. Meteorological data were also provided from an automatic meteorological station on the $R V$, therefore, among others, information concerning the position, speed and direction of the $R V$ were also available for identifying situations of contamination due to the emissions from the ship itself. In order to fully examine the data recorded, each single cruise campaign will be considered in the next sections focussing on concentrations of different aerosol size fractions (fine and coarse) levels. These data were integrated with variations in the major PM transition (heavy) metals along with their distribution within finer and coarser

aerosols during the journey. Spatial and temporal variations of the recorded data will be furthermore reported highlighting the events that were identified as the main influencing factors. Instances of exceptionally high or low, aerosol concentrations during the cruise have been investigated using the back-trajectory analysis and the NAAPS based maps (http://www.nrlmry. navy.mil/ aerosol/). The Hybrid single-particle Lagrangian integrated trajectory model (HYSPLIT) available at the NOAA Air Resources Laboratory (ARL) (Air Resources Laboratory, 2010), was used to calculate $48 \mathrm{~h}$ backward-trajectories for the $R . V$. Urania's position at each day hours during each oceanographic campaigns. The calculations were performed using the READY website making use of the archived FNL meteorological datasets. The interpretation of the aerosol size spectra was also supported by the Navy Aerosol Analysis and Prediction System (NAAPS) predicting the distribution of tropospheric aerosols and its surface concentration in terms of dust, sulphate or smoke concentration. Specific events were also analyzed in relation to the NCEP based 700 mbar level geopotential height and temperature (http://www.cdc.noaa.gov/) in order to assess their seasonal differences and the main circulation patterns driving these events through the Mediterranean Basin.

\section{Results and Discussion}

Fig. 1 shows the spatial variation of $\mathrm{PM}_{10}$ concentrations observed during five cruise campaigns performed, from 2003 to 2007, in the Mediterranean basin along the reported tracks. Fig. 2 otherwise reports a summary of Max, mean and min values recorded for each detected element. $\mathrm{PM}_{10}$ concentrations ranged very wide from 8.7 to $56.6 \mu \mathrm{g} \mathrm{m}^{-3}$ with a mean value of $27.8 \mu \mathrm{g} \mathrm{m}^{-3}$ across the whole Mediterranean Basin. Away from major port cities (see Fig.1) the higher $\mathrm{PM}_{10}$ mass levels were recorded at the extremity of the Basin where dust intrusions from North Africa and smoke plumes from biomass burning in

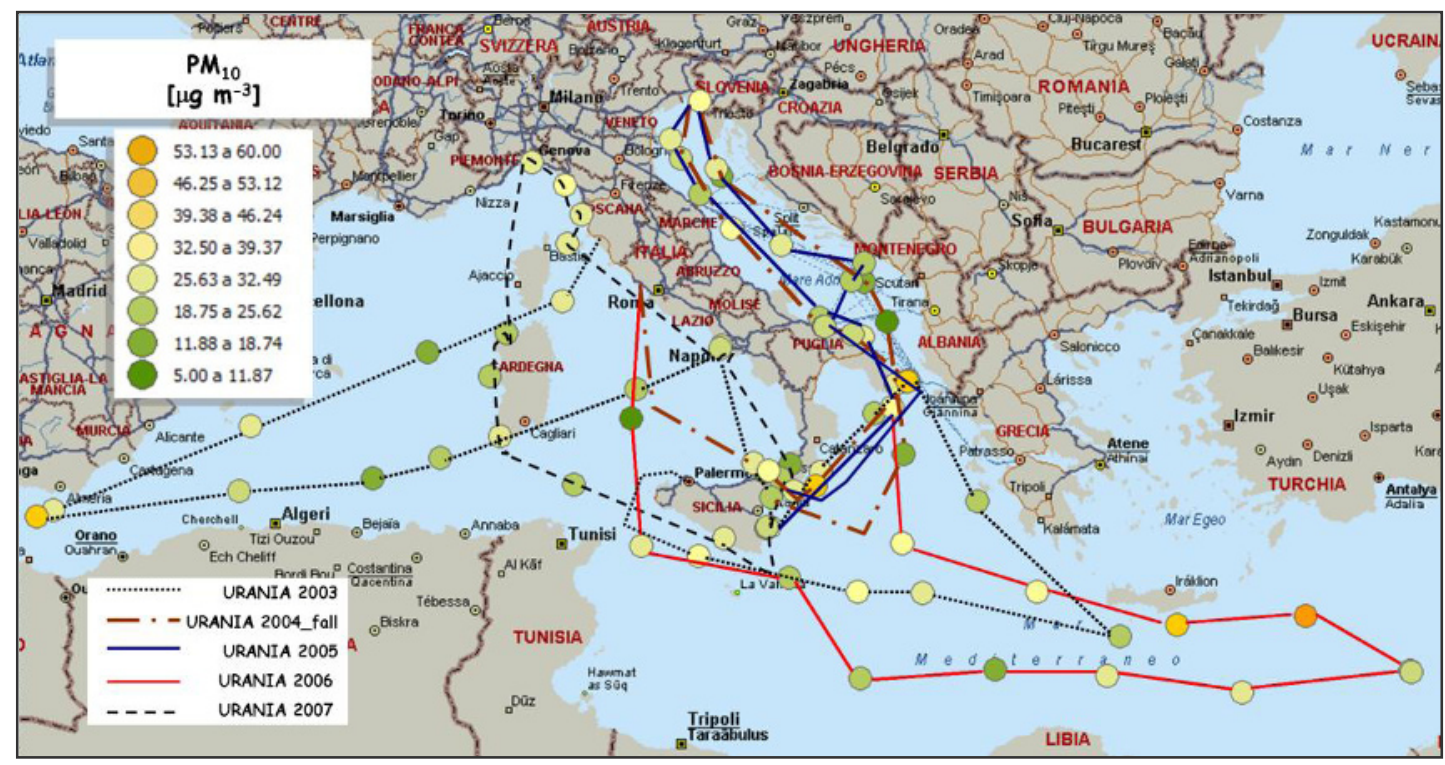

Fig.1 Spatial variation of $\mathrm{PM}_{10}$ concentrations observed during five cruise campaigns performed, from 2003 to 2007 , in the Mediterranean basin along the reported tracks 
sub-Saharan Africa and Greek have been identified as the main sources of contribution. During the 2003 cruise campaign, the Urania Research Vessel followed firstly a track along south-eastern Mediterranean sea from Sicily to Creta island, passed through the Strait of Messina and then, after a brief stop at Napoli harbour, continued in the western Mediterranean sector until the Strait of Gibraltar and returned back ending to the Livorno harbour (Fig1). The whole cruise involved 20 days during summer 2003 from $6^{\text {th }}$ to $27^{\text {th }}$ of August, during which the temperature was quite high (23-30 ${ }^{\circ} \mathrm{C}$ ) and the high-pressure system (anti-cyclone) prevailed. The hot and dry persistent weather conditions, well-known as the 2003 "heat-wave", trigged numerous wildfires, enhanced the pollution accumulation in the boundary layer and caused a lot of premature deaths (Kovats et al., 2006).

As it can be observed in Fig.2, during the 2003 cruise campaign, with the only exception of $\mathrm{Cr}$ and $\mathrm{Ni}$, mean values of metal concentrations were lower in comparison with those recorded during the other campaigns. The 2004 Urania Cruise Campaign covered the Adriatic Sea along the track reported in Fig.1. The Adriatic Sea, and particularly the northern part, is a polluted area. In many ways the Adriatic Sea is a microcosm of the Mediterranean Sea, with a range of geographical complexities and anthropogenic pressures. During this cruise we found both the highest fine concentrations and the typical marker ratio of $\mathrm{V} / \mathrm{Ni}$ (equal to $2.0-4.0$ (Pandolfi et al., 2009)) for shipping emissions, during the passage through the Messina Strait. This occurrence showed the large influence coming from the local ship traffic of this area. The 2005 cruise path was identical to the 2004 one in the Adriatic Sea with the difference that the 2005 cruise campaign was performed during summer (from $17^{\text {th }}$ June to $1^{\text {st }}$ July) with calm sea conditions and stable atmospheric conditions and no rain. Fine concentrations ranged from 7.0 to $15.9 \mu \mathrm{g} \mathrm{m}^{-3}$ with corresponding coarse values from 7.8 to $22.0 \mu \mathrm{g} \mathrm{m}^{-3}$ without any relevant increasing level. A larger contribution of coarse fraction on average was found for all the detected elements. With the only exception of $\mathrm{Al}$ and $\mathrm{Sb}$, all other detected metals showed a larger concentration than those recorded during the 2004 cruise campaign (see Fig.2). In particular, during four days over the whole cruise campaign, $\mathrm{Ni}$ concentrations were higher than the target value (>20 $\mathrm{ng} \mathrm{m}^{-3}$ ) reported in the European Directive 2008/50/EC. During the 2006 cruise campaign, the Urania Research Vessel followed a track along south-eastern Mediterranean sea. Starting from Civitavecchia (Rome) the ship passed firstly under Sicily and then continued in the western Mediterranean sector until almost the Cyprus island and returned back ending at the Gallipoli harbour, in southern Puglia region (Fig.1). In this period, the air masses crossing the Urania positions, arrived from the eastern part of Europe where, as supported by the NAAPS-based smoke and sulphate map, large wildfire events occurred. During this period the air quality of the Mediterranean Basin was affected by an high anthropogenic influence also coming from the eastern Europe. It is relevant to highlight that $\mathrm{Cr}, \mathrm{Pb}$ and $\mathrm{Ni}$ concentrations were quite higher than those observed during the other cruise campaigns and that Ni levels, in particular from $12^{\text {th }}$ to $13^{\text {th }}$ of July, reached values twice higher than the target value $\left(20 \mathrm{ng} \mathrm{m}^{-3}\right)$. The 2007 cruise campaign was entirely performed within the Tyrrhenian Sea from the $13^{\text {th }}$ of September to the $2^{\text {nd }}$ of October 2007. The whole cruise campaign experienced 20 days during which about a $48 \mathrm{~h}$-stop close to the main Italian harbours within the Tyrrhenian Sea was taken.. Remarkable high levels in all detected metals were recorded in the early days of the cruise campaign (from $12^{\text {th }}$ to $16^{\text {th }}$ September) when the Urania Research Vessel was close to the Naples harbour. With the only exception of $\mathrm{Cr}$, other detected metals after the $16^{\text {th }}$ September showed a significant decreasing in their levels whose mean values were hereafter comparable to those recorded during the other cruise campaigns.

\section{Conclusion}

Observations performed across the Mediterranean Basin along five cruise campaigns from 2003 to 2007 on board the R.V. Urania resulted in a sample of 83 daily observations in $\mathrm{PM}_{2.5}$ and $\mathrm{PM}_{2.5-10}$ along with trace metals $\mathrm{PM}$ content and meteorological parameters.

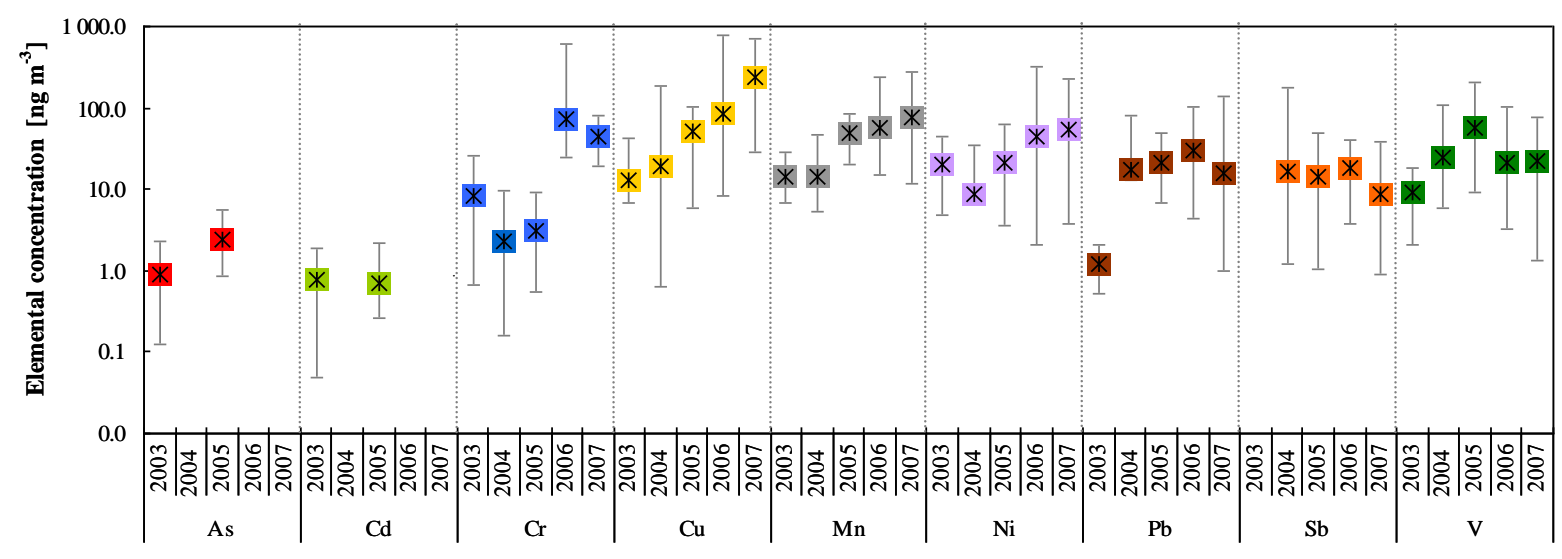

Fig.2 Max, mean and min values referring, for each cruise campaigns, to $\mathrm{PM}_{10}$-associated trace elements 
Results showed different values in both fine and coarse fractions ranging from 2.6 to $40.4 \mu \mathrm{g} \mathrm{m}^{-3}$ and from 1.6 to $31.2 \mu \mathrm{g} \mathrm{m} \mathrm{m}^{-3}$, respectively. $\mathrm{PM}_{10}$ concentrations showed similar values along the whole Mediterranean Basin with a larger contribution of fine fraction in the Eastern side compared to the Western sector where the coarse fraction prevailed. Ship emissions might be one of the explanations for the high fine concentrations observed in air with trajectories of marine origin. Coarse PM concentrations were otherwise specifically related to Saharan dust intrusion within the Marine Boundary Layer. The relative contributions of anthropogenic and natural emissions within the Mediterranean region varied greatly with location, season and meteorological conditions. Considering the primary role played by atmospheric processes in supplying trace metals, further experimental measurements over Mediterranean sea will remain a challenge to improve our knowledge on contributions to the background aerosol levels in this region. The record of data herein presented holds a relevant interest in that it fills the observation gaps over the Mediterranean Basin.

\section{References}

Guerzoni, S., Chester, R., Dulac, F., Herut, B., LoyePilot, M-D., Measures, C., Migon, C., Molinaroli, E., Moulin, C., Saydam, C., Soudine, A. and Ziveri, P., 1999. The role of atmospheric deposition in the biogeochemistry of the
Mediterranean Sea, Progress in Oceanography, 44: 147-190.

Herut, B., Krom, M. D., Pan, G. and Mortimer, R., 1999. Atmospheric input of nitrogen and phosphorus to the Southeast Mediterranean: sources, fluxes, and possible impact. Limnol. Oceanogr., 44: 1683-1692.

Jickells, T., 1995. Atmospheric inputs of metals and nutrients to the oceans: their magnitude and effects. Marine Chemistry, 48: 199-214.

Kouvarakis G, Tsigaridis K, Kanakidou M, Mihalopous N. Temporal variation of sourface regional background ozone over Crete Island in the southeast Mediterranean. J Geophys Res 2000; 105(D4): 43994407.

Kovats, S.R.; Ebi, K.L. Heatwaves and public health in Europe. European. J. Pub. Health. 2006, 16, 592-599.

Marmer E and Lanmann B. Impact of ship emissions on Mediterranean summertime pollution and climate: A regional model study. Atmos Environ 2005, 39: 46594669.

Pace, G.; Meloni, D.; di Sarra, A. Forest fire aerosol over the Mediterranenan basin during summer 2003, J Geophys Res 2005; 110 D21202 doi:10.1029/2005JD005986.

Pandolfi M, Gonzalez-Castanedo Y, Alastuey A, Rosa Jdl, Mantilla E, Pey J, Querol X. Contribution from shipping emissions to ambient $\mathrm{PM}_{10}$ and $\mathrm{PM}_{2.5}$ at multiple sites at Algeciras Bay (S. Spain) by using chemical speciated data, wind data and PMF model. Environ Sci Technol 2009; submitted. 